\title{
АНАЛИЗ ВЛИЯНИЯ РАСПОЛОЖЕНИЯ ВЫРАБОТКИ НА ОПАСНОСТЬ РЕАЛИЗАЦИИ ГАЗОДИНАМИЧЕСКИХ ЯВЛЕНИЙ
}

\author{
А.К. Федосеев \\ Горный институт УрО РАН, г. Пермь
}

\begin{abstract}
Аннотация: При разработке практически всех месторождений калийных солей одной из наиболее сложных задач обеспечения безопасности горных работ является проблема газодинамических явлений (ГДЯ). С ГДЯ связаны внезапные выбросы соли и газа, динамические разрушения, которые сопровождаются интенсивным газовыделением и возможным выносом разрушенной породы в горную выработку. Геологическими предпосылками развития ГДЯ зачастую являются слоистое строение массива соляных пород, наличие прослоев и слоев соляных глин.

Математическое моделирование геомеханических процессов в условиях приконтактного скопления свободного газа выполнялось применительно к условиям рудника «Усольского калийного комбината» с учетом экспериментальных оценок давления свободных газов и начальной скорости газовыделения в породах кровли выработок.

Деформирование слоистого соляного массива, подработанного камерной системой разработки, описывалось моделью идеальной упруго-пластичной среды с внутренним трением. В качестве критерия пластичности в области сжатия использовалась параболическая огибающая кругов Мора. При численной реализации деформирование глинистых контактов моделировалось контактными элементами Гудмана. При проведении расчетов основной акцент сделан на оценку влияния местоположения выработки на характер реализации ГДЯ.
\end{abstract}

Ключевые слова: калийные рудники, газодинамические явления, напряженно-деформированное состояние, математическое моделирование, критерии обрушения.

Внезапные выбросы соли и газа относятся к числу явлений, несущих наибольшую угрозу здоровью и жизни шахтеров на соляных месторождениях. Несмотря на внедрение результатов научных исследований в практику ведения горных работ, которое позволило свести к минимуму количество газодинамических явлений (ГДЯ), при эксплуатации новых рудников с их уникальными геологическими и горнотехническими условиями отработки появляются новые виды ГДЯ, ранее не встречавшиеся или редко встречавшиеся в практике ведения горных работ. Так, с момента начала ведения подготовительных и очистных горных работ на руднике ООО «ЕвроХим - Усольский калийный комбинат» уже зафиксировано 8 газодинамических явлений. По месту разрушения все случаи ГДЯ произошли из кровли при проходке подготовительных и очистных выработок по пласту КрII. Все очаги газодинамических явлений в виде внезапных обрушений пород кровли сопровождались газовыделением и были приурочены к приконтактным (прислоевым) скоплениям свободного газа, расположенным в пластах КрI и KpI-A'.

Формирование очага ГДЯ в кровле выработки происходит за фронтом очистных работ, когда вследствие деформации кровли начинается расслоение породного массива по границам пластов и глинистым прослоям (рис. 1, а). При раскрытии одного или более глинистых контактов в образовавшуюся полость мигрирует газ из окружающего массива (рис. 1, б). Эксперименты показывают, что, как правило, давление газа в раскрытом контакте превышает атмосферное давление в выработке, а значит вносит дополнительный вклад в обрушение кровли. Очевидно, что для любых горногеологических условий и физико-механических свойств пород можно определить предельное давление газа $\mathrm{P}_{\mathrm{c}}$ (рис. 1, в) в раскрытом контакте, при котором возможна реализация ГДЯ.

Для оценки возможности реализации ГДЯ из кровли выработанного пространства проводилось математическое моделирование изменения напряженно- 
деформированного состояния (НДС) и разрушения неоднородного слоистого породного массива, вмещающего систему горных выработок. При анализе НДС подработанной толщи необратимый характер деформирования соляных пород описывался моделью идеальной упруго-пластичной среды с внутренним трением. В качестве критерия пластичности в области сжатия использовалась параболическая огибающая кругов Мора [1]. Зоны локализации пластических деформаций, как общепринято в геомеханике, отождествлялись с процессами трещинообразования, соответственно, за счет сдвига и растяжения.

a)

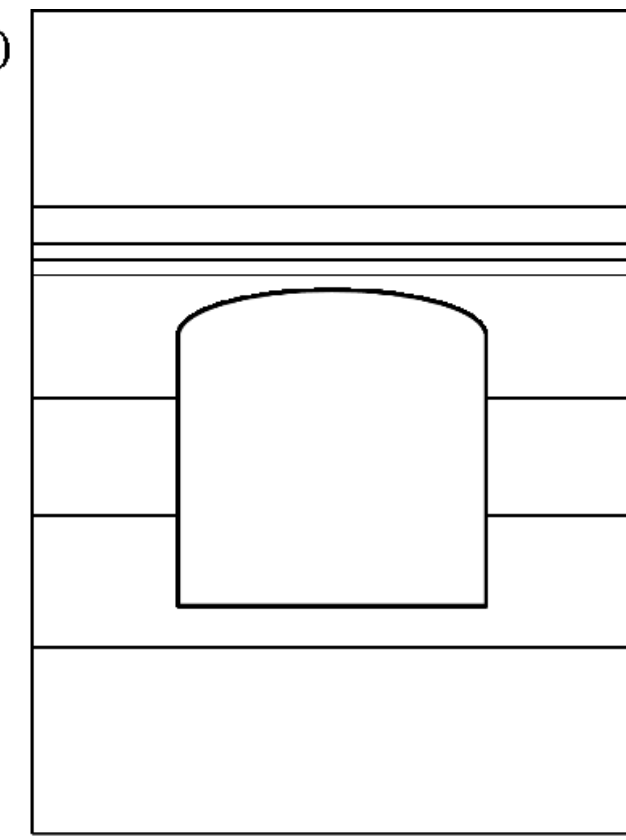

б)

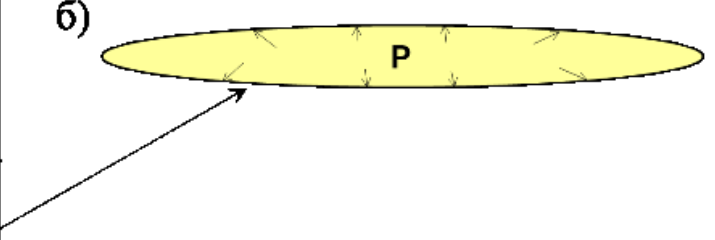

B)

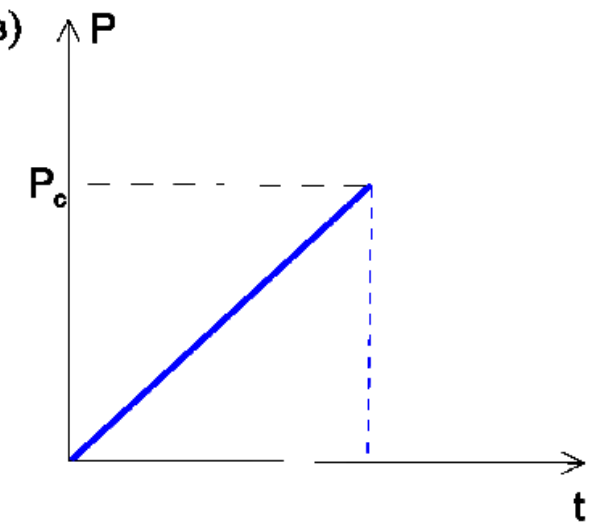

\section{$\longrightarrow$ - гравицы пластов; глинистые прослои}

Рис. 1. Моделирование давления газа в раскрытом глинистом контакте

При численной реализации деформирование глинистых контактов между слоями моделировалось контактными элементами Гудмана $[2,3]$.

Поступление газа моделировалась постепенным увеличением давления Р в раскрытой части контакта (рис. 1, б, в). На каждом шаге приращения давления решалась квазистатическая задача по определению приращения перемещений и напряжений.

В качестве первого условия обрушения пород в выработанное пространство принимался выход зоны действия растягивающих напряжений на обнажение. Реализация этого критерия осуществлялась путем специальной организации вычислительного итерационного процесса: на каждой итерации из рассмотрения исключались (обнулялись) конечные элементы, примыкающие к границе кровли выработанного пространства [4].

В случае достижения областью сдвиговой трещиноватости «раскрытого» глинистого контакта происходит обрушение пород в выработанное пространство [5]. Учет данного критерия обрушения также реализован в расчетной процедуре, путем локализации и последующего исключения из расчетов областей, ограниченных «раскрытым» глинистым прослоем и зонами сдвиговой трещиноватости.

Принятые подходы апробировались применительно к условиям рудника «Усольского калийного комбината» при камерной отработке сильвинитового пласта КрII. Ширина камер составляла 5.5 м и 3.2 м. Ширина междукамерных целиков изменялась от 5.8 м до 8 м для камер шириной 3.2 м и от 8.6 м до 14.6 м для камер шириной 5.5 м. Средняя вынимаемая мощность составляла 5.5 м. 
На основе многовариантного геомеханического моделирования процесса формирования очагов ГДЯ проводилась оценка условий, определяющих предпосылки к внезапным выбросам соли и газа из кровли выработки. При этом первым вопросом, требовавшим рассмотрения, являлась оценка влияния местоположения выработки относительно шахтного поля на развитие процессов ГДЯ. Для учета этого влияния были рассмотрены три расчетные схемы (рис. 2, рис. 3), описывающие основные возможные ситуации:

- схема А: выработка в зоне полной подработки. В этом случае с учетом симметрии можно рассматривать половину камеры и целика;

- схема Б: временная краевая часть выработанного пространства (только что отработанная камера). Симметрия имеет место только по одной из боковых границ. Расстояние от контура выработки в направлении ненарушенного массива должно составлять не менее 3-х ее поперечных размеров;

- схема В: одиночная выработка, штрек. С учетом симметрии также, как и в схеме А, можно рассматривать половину камеры; расстояние от выработки до боковой границы, как и в схеме Б, должно составлять не менее 3-х ее поперечных размеров.

Во всех случаях рассматривалась подработанная соляная толща, находящаяся под действием массовых сил интенсивностью $\gamma_{i}\left(\gamma_{i}-\right.$ плотность пород). На расстоянии $3 * \mathrm{~m}(\mathrm{~m}$ - вынимаемая мощность) выше кровли камеры породный массив отражался весом вышележащей толщи, что значительно уменьшало расчетную область и, соответственно, снижало временные затраты на математическое моделирование.

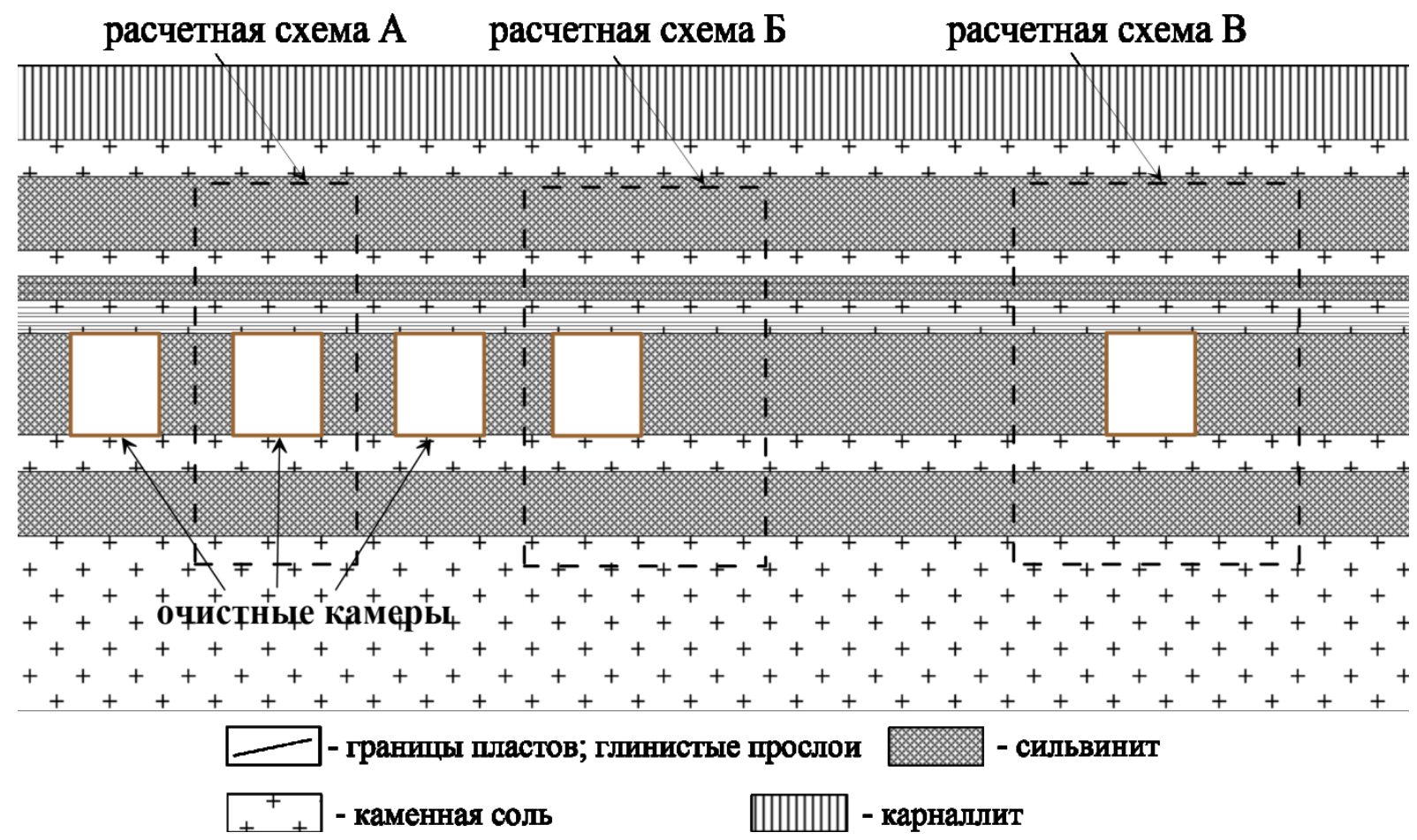

Рис. 2. Схематичное положение расчетных схем в массиве

Сравнение характера обрушения для различных расчетных схем (схемы А, Б, В) при ширине камеры и целика 5.5 и 8.6 м, соответственно, и расстоянии до раскрытого контакта 0.9 м, представлено на рис. 4. Можно отметить, что в случае одиночной выработки (рис. 4 в) увеличивается высота возможного обрушения; для камеры на границе отработанного участка (рис. 4 б) основное отличие связано с 
несимметричностью постановки. Оценки критического давления $\mathrm{P}_{\mathrm{c}}$ при различных параметрах отработки (рис. 5) показывают, что, несмотря на некоторые отклонения (большие - в случае одиночной выработки и меньшие - для выработки на границе отработанного участка), полученные закономерности сохраняют свою значимость вне зависимости от использованной расчетной схемы, и играют меньшую роль по сравнению, например, с шириной пролета выработки. При этом с увеличением расстояния до раскрытого газонасыщенного контакта значение критического давления практически перестает зависеть от положения выработки в пределах шахтного поля.
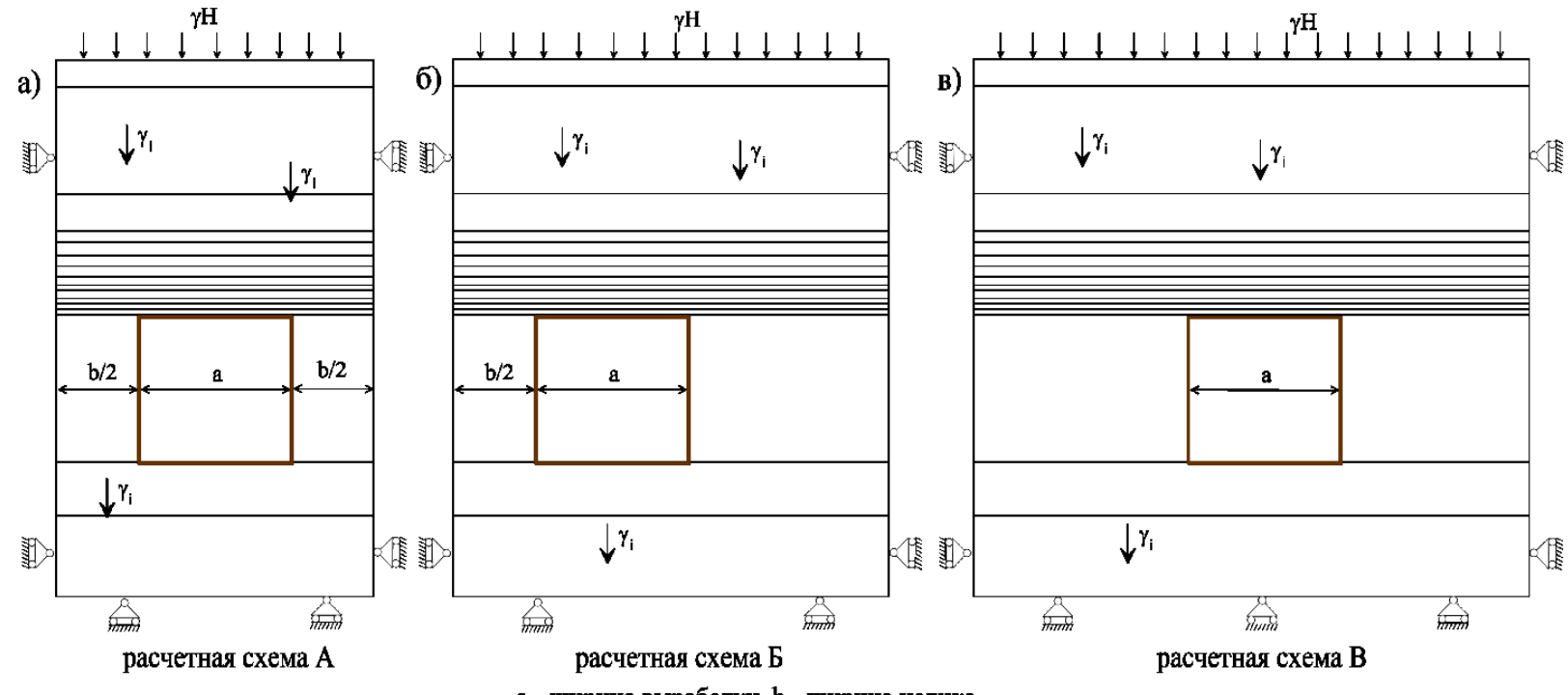

a - шширина выработки, b - пиирина целика

Рис. 3. Расчетные схемы

Таким образом, проведенные исследования свидетельствуют об ограниченном влиянии местоположения выработки по сравнению с другими факторами (ширина пролета выработки, расстояние до газонасыщенного контакта и др.), и дальнейшие исследования могут проводиться на примере очистной камеры, расположенной в зоне полной подработки, что, ввиду симметрии задачи, позволяет существенно уменьшить объем вычислительных ресурсов.
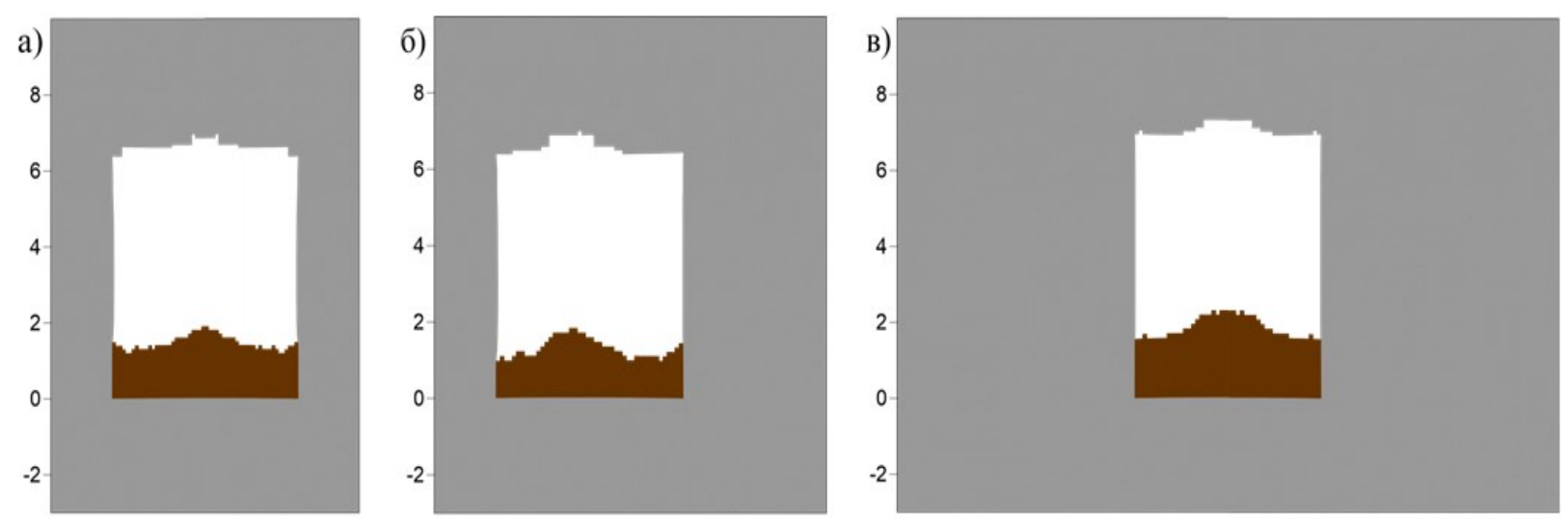

- обрушенные породы

- выработанное пространство

Рис. 4. Характер обрушения из кровли выработки для различных расчетных схем:

а) для камеры в зоне полной подработки; б) камеры на границе отработанного участка;

в) одиночной выработки 


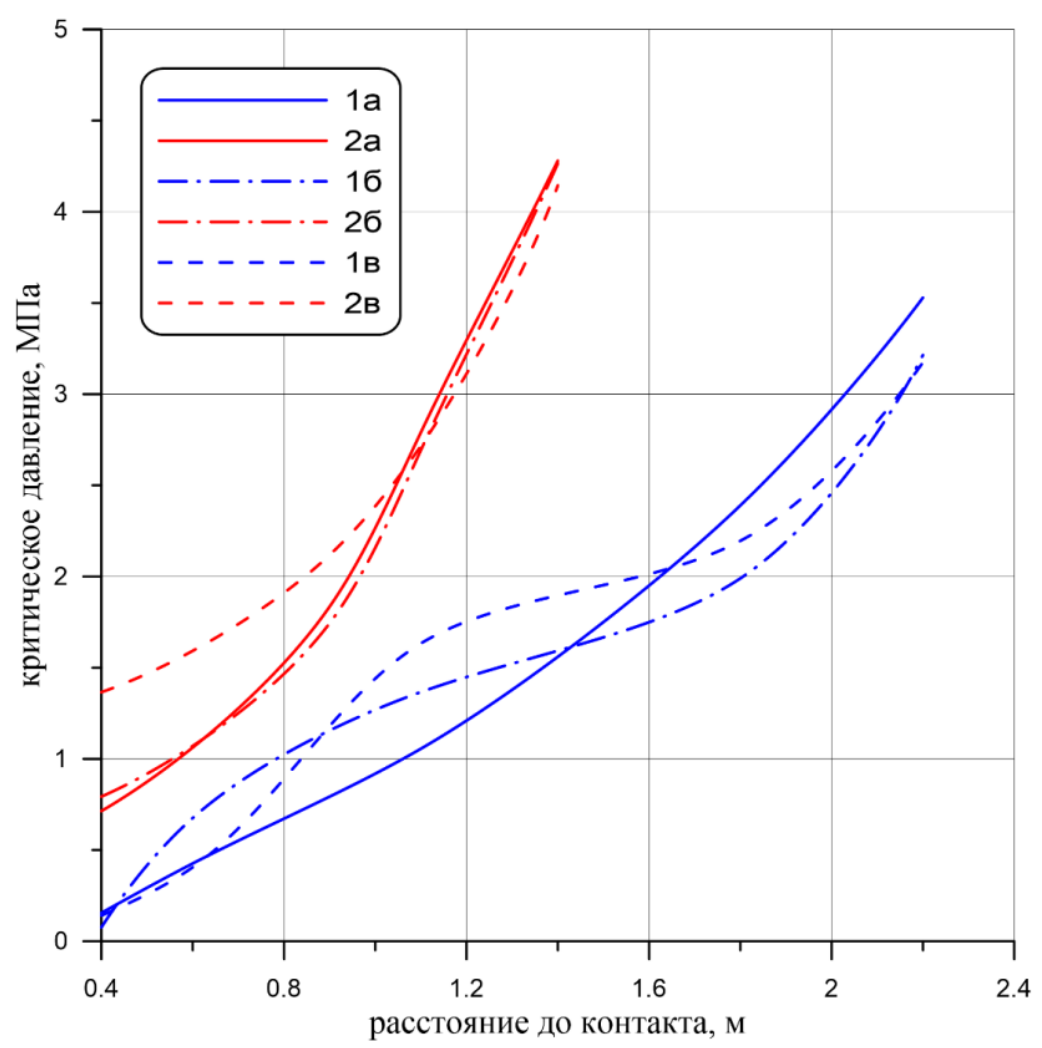

Рис. 5. Изменение критического давления в зависимости от расстояния до раскрытого газонасыщенного контакта при ширине пролета выработки 5.5 м (графики 1а, 16, 1в) и 3.2 м (графики 2а, 2б, 2в) при различных положениях выработки в пределах шахтного поля: графики 1a, 2a - выработка в зоне полной подработки; графики 1б, 2б - выработка на временной границе отработанного участка; графики 1в, 2в - одиночная выработка

Работа выполнена при финансовой поддержке РФФИ (грант №18-05-00371 А) и госзадания №0422-2019-0148-C-01

\section{БИБЛИОГРАФИЧЕСКИЙ СПИСОК}

1. Кузнецов Г.Н. Механические свойства горных пород. - М.: Углетехиздат. - 1947. - 180 с.

2. Goodman R.E. The mechanical properties of joins // Adv. Rock Mech. - 1974. - V.1, Pt A. - P. 127-140.

3. Groth T. Description and applicability of the BEFEM code. // Applied Rock Mechanics Mining: Proceedings Conference, Lulea. 1-3 June, 1980. - London, 1981. - P. 204-208.

4. Baryakh A.A., Fedoseev A.K. Sinkhole Formation Mechanism // Journal of Mining Science. - 2011. - V. 47, № 4. - P. 404-412.

5. Барях А.А., Шумихина А.Ю., Токсаров В.Н., Лобанов С.Ю., Евсеев А.В. Критерии и особенности разрушения слоистой кровли камер при разработке Верхнекамского месторождения калийных солей // Горн. журн. - 2011. - № 11. - С. 15-19. 